\title{
Los gastos del Leviatán: Breve aproximación histórica a la evolución del presupuesto gubernamental siglo XIX-XXI
}

\author{
Javier Saravia Salazar \\ Universidad Nacional Mayor de San Marcos, Lima, Perú \\ javiersaraviasal@gmail.com
}

\begin{abstract}
RESUMEN
El presupuesto es una de las herramientas de gestión más importantes que tiene el Estado para su supervivencia y la de sus ciudadanos. Su desarrollo y perfeccionamiento se dan de la mano con los cambios políticos, económicos y sociales que experimenta el Estado. De un estado mínimo donde el gasto público está subordinado a la voluntad del Ejecutivo, pasamos a un sistema de presupuesto público en donde se incorporan diferentes actores políticos en la fijación del gasto público. En las siguientes líneas ofrecemos una aproximación a la evolución del presupuesto público, con especial atención en las transformaciones del Estado y en la aparición de nuevos actores políticos que intervienen en la elaboración es su creación.
\end{abstract}

Palabras clave: Presupuesto Público, siglos XIX-XXI, Estado, actores políticos

\section{The Leviathan expenses: Brief historical approach toward the evolution of the 19th - 21st Century Government budget}

\begin{abstract}
The budget is one the most important management tools that the State has to its survival and that of its citizens. Its development and perfectionism go hand in hand with the political, economic, and social changes experienced by the State undergo. From a minimum state where the public expending is subordinate to the Executive Power willingness, we move to a public budget system that incorporate different political actors in the setting of public expending. In the following lines we offer an approach to the public budget evolution, with special attention in the state transformation and the appearance of new political actors that intervene in the elaboration of its creation
\end{abstract}

KeYwords: Public Budget, XIX-XXI centuries, State, political actors 


\section{Introducción}

Dentro de los estudios sobre el Estado desde las ciencias sociales, ha aparecido un renovado interés por explorar al aparato público, así como sus instituciones y el perfeccionamiento de sus instrumentos de administración y gestión. En esta línea de ideas, nos concentraremos en las siguientes páginas en ofrecer una introducción a la evolución histórica del presupuesto gubernamental en nuestro país. Del mismo modo pretendemos esbozar una propuesta metodológica para poder analizarlo y nos ayude a ofrecer un panorama más completo de su utilidad como fuente histórica, no tanto como un registro estadístico, muchas veces inexacto, sino como un producto de la lucha entre diferentes actores políticos.

A medida que el Estado se afianza comienzan a aparecer nuevos actores que obligan al Estado a perfeccionar sus herramientas administrativas, al menos formalmente, para dar luego lugar a cambios reales. En esta línea se construyen relaciones tensas entre los miembros de la élite, aparecen nuevos grupos de presión al Estado como la burocracia, la movilización social, y la intelectualidad, que ponen en cuestión el orden tradicional caudillista.

El objetivo de estas líneas es tomar al "presupuesto público» como un objeto de estudio, en sí mismo, con su propia historicidad, para rastrear su origen, su implementación en nuestro país y evolución hasta la actualidad, a la par que el Estado y las herramientas de la "gestión pública» se consolidan. Resaltándose el hecho que esta gradual evolución, aplicando nuevos criterios de orden administrativo, se produce a medida que el Estado se consolida y diversifica sus funciones y, sobretodo, que es con el pasar del tiempo que más actores políticos intervienen en su diseño. Finalmente, queremos hacer énfasis en la necesidad de una metodología de carácter histórico para dar cuenta de los diversos actores que intervienen en la formulación del presupuesto público.

\section{Aspectos generales del presupuesto}

La actitud de "presupuestar» parece estar implícita en las actividades humanas desde las primeras civilizaciones humanas, puesto que desde los imperios, babilónico, egipcio y romano se debía planear las actividades de manera acorde con los cambios climáticos para aprovechar las épocas de lluvias y asegurar la producción de alimentos. Los imperios, egipcio y romano, impusieron diversos tipos de impuestos basados en los recursos de sus habitantes y con estos recursos planeaban las posibles guerras que enfrentarían. En la Edad Media se desarrolló el comercio y el intercambio de bienes a través del dinero, se instauraron formas de registro contable en cual se contabilizaban los ingresos y los 
egresos para determinar las utilidades de cada negocio ${ }^{1}$. Según Kresalja y Ochoa (2012) al ser el presupuesto un "acto de control», es una "criatura de la democracia», porque si hay un derecho que surge con el desarrollo de aquella en el siglo XIX es el derecho presupuestal, que es una institución eminentemente democrática.

El presupuesto como objeto de estudio independiente tiene aún poco desarrollo. Al hablar del presupuesto público por lo general los historiadores como el resto de los investigadores sociales, se concentran en los datos contenidos en él para reconstruir los hechos de sus respectivos temas de investigación. Por lo que el análisis de su evolución ha estado mayormente ligado a las ciencias administrativas y contables.

Tras las reformas estructurales de los años noventa, con la aparición de un nuevo modelo de Estado y un proceso de modernización que busca en buena medida replicar los instrumentos de gestión de la esfera privada en la estatal, la bibliografía dejó de lado la perspectiva de largo plazo y por ende los trabajos de corte histórico, concentrándose más en los aspectos técnicos y las etapas de la formulación del presupuesto público como lo conocemos en la actualidad. Inclusive los trabajos de las ciencias sociales se han concentrado en los procesos de participación ciudadana en el presupuesto público (presupuesto participativo), el impacto del incremento presupuestal en la dinámica local y regional, así como en los mecanismos y políticas de transparencia en el gasto público de las diferentes entidades y gobiernos locales y regionales.

Desde el lado de la Historia el análisis del presupuesto público se inserta propiamente en la historia política y en la historia económica, conscientes de que ambas dimensiones se mezclan, los trabajos históricos no han sido del todo claros para explicar dos factores convenientemente, el primero de ellos enfocar la evolución del pensamiento administrativo y como transforma al aparato público tanto en los aspectos de gestión como políticos; y en segundo lugar como han evolucionado los instrumentos de gestión y como se inserta su origen con la evolución del Estado y la aparición de nuevos actores políticos en escena ${ }^{2}$.

1 Joseph Vlaemminck, en su obra Historia y doctrinas de la contabilidad, menciona que en los registros de los Massari de Génova (1340) llevados a la venenciana aparecen cuentas de presupuesto. Luego cita al monje benedictino Angelo Pietra como el primer autor que se preocupa de la previsión de ingresos y gastos (siglo XVI) y a Lodovico Fiori como el autor que habla de la utilidad de los presupuestos (1636).

2 Esta es aun una historia en construcción, y tanto historiadores como abogados y economistas desde sus respectivas áreas han apuntado a descripciones parciales o intentos exploratorios sobre la evolución del aparato público y sus instrumentos de gestión. Sin embargo, tras las reformas estructurales, hubo un punto de corte que eliminó el enfoque de largo plazo priorizando los estudios de carácter técnico. Esto en nuestro país, por ejemplo, en pleno contexto de implementación de la Ley Servir, llevo a muchos especialistas en administración, a obviar la existencia de procesos de modernización del servicio público desde las primeras décadas del siglo XX. Este sesgo al momento de evaluar el impacto y la originalidad de las reformas en la estructura estatal no permitió enfocarse en ciertas patologías estructurales del sistema estatal como el clientelismo y la corrupción, y que pese a los tecnicismos del sistema persistieron y crecieron con las reformas. En este orden ideas es interesante constatar como autores que apoyaron las reformas como Joseph Stiglitz y Francis Fukuyama, reconocen que para la aplicación de las mismas era necesario el conocimiento de la "cultura política» de donde se va a aplicar y los problemas estructurales que tenían previamente, pues por sí solas el paquete de reformas no podía tener éxito. Ver al respecto: Stiglitz, Joseph 
Sin pretender ser exhaustivos, ofrecemos un breve recorrido por algunos de los textos que consideramos han tocado con mayor interés al presupuesto público, desde una perspectiva histórica que contribuye a una visión más integral del presupuesto en sus aspectos tanto técnicos como políticos. De los trabajos mencionados, debemos precisar que la mayoría de ellos se concentra en el presupuesto público en la etapa republicana, cuando el aparato estatal aún era poco tecnificado y se estaba forjando aún la institucionalidad.

Jorge Basadre en su monumental obra Historia de la República (1969), dedicó muchas líneas que nos brinda información estadística, pero sobre todo se detuvo en los aspectos políticos coyunturales en torno a la administración pública y su impacto en el uso de instrumentos como el presupuesto. Javier Tantaleán (1983) en Política económica-financiera y la formación del Estado: siglo XIX, nos ofrece un análisis profundo a la lógica de lo que él denomina "Estado caudillista» y los criterios de la Hacienda Pública en los primeros años republicanos, del mismo modo nos ofrece valiosos datos estadísticos, del presupuesto público y sobre la administración contable de los años del «boom guanero». Quizás la obra de mayor envergadura sobre la evolución del presupuesto público sea la del economista Fernando Arce (1990) El presupuesto gubernamental en el Perú. Historia y propuestas, que aborda de manera dinámica e informada la evolución del presupuesto desde sus antecedentes en la Hacienda Pública colonial hasta la etapa moderna republicana previa a las reformas estructurales de los años noventa. Carlos Contreras (2012) La economía pública en el Perú después del guano y del salitre. Crisis fiscal y elites económicas durante su primer siglo independiente, en donde se desarrolla en un contexto específico el funcionamiento de la política del gasto público y la aparición de actores políticos influyentes al momento de fijar las asignaciones presupuestarias a las diferentes carteras ministeriales. Finalmente, la obra de Miriam Salas (2016) El presupuesto, el Estado y la nación en el Perú decimonónico y la corrupción institucional, 1823-1879, en donde explora en un periodo bastante específico el perfeccionamiento de herramientas como el presupuesto para la administración pública, la delimitación de las funciones del Ministerio de Hacienda y el análisis de la corrupción como un problema estructural para la buena administración de lo público en la joven república peruana.

(2003) La semilla de la destrucción. La década más próspera de la historia como causa de la crisis económica actual. Buenos Aires: Taurus; y Fukuyama, Francis (2004) La construcción del Estado. Hacia un nuevo orden mundial en el siglo XXI.

3 La preocupación de Basadre por el presupuesto se produce desde sus días de estudiante de derecho, así es como lo refiere en la quinta edición de Historia de la República: «como alumno de la Cátedra de Finanzas y Legislación Financiera en el Perú preparé en 1927 para el catedrático Hernando Lavalle un largo estudio sobre el crecimiento de los Presupuestos (...) publicado luego fragmentariamente en la Revista de Ciencias Jurídicas y Sociales». 


\section{Evolución del presupuesto en nuestro país ${ }^{4}$}

Como hemos señalado en líneas precedentes la historia del presupuesto público en nuestro país va de la mano con la historia política, la evolución del Estado y la aparición a través del tiempo de nuevos actores dirimentes en la fijación y orientación del gasto público. Por ello, de manera algo simplista podemos plantear que en la fijación del presupuesto se parte en su origen de la acción discrecional del gobernante y de un número reducido de actores, a la fijación de gastos permanentes para el Estado, la diminución de la discrecionalidad del Ejecutivo en materia presupuestaria, y el aumento de actores intervinientes en las decisiones sobre el gasto público. Por definición el Presupuesto Público del Perú debe prioritariamente «mejorar la calidad de vida de los peruanos» y atender principalmente las "necesidades básicas de los peruanos más pobres».

Si bien la historia del gasto estatal tiene antecedentes en la época virreinal dignos de mención paras dar cuenta de la evolución de las ideas contables y la manera de entender el gasto público en aquella época y por ende dar una panorámica más completa del desarrollo del pensamiento administrativo y contable en nuestro país, nos concentraremos en esta oportunidad de describir la evolución del presupuesto y proponer una periodificación a partir del origen de la República y el inicio de la vida política independiente de nuestro país. Consideramos, partiendo de la información brindada por Arce (1990), Contreras (2012) y Salas (2016), una periodificación en tres grandes bloques para el presupuesto gubernamental: 1) la etapa Hacendaria Tradicional (1821 a 1919); 2) la etapa moderna (1920-1993) y 3) la etapa contemporánea (desde 1993). Para establecer esta clasificación nos concentraremos en desatacar la presencia de una mayor cantidad de actores a la hora de establecer el gasto fiscal y la asignación presupuestaria para cada cartera ministerial y, además, en el perfeccionamiento de las herramientas de gestión.

\subsection{La etapa hacendaria tradicional (1821 a 1919)}

La República significó para el Perú la ruptura con el poder de la metrópoli española, sin embargo, esta ruptura no significó de inmediato un cambio significativo en las relaciones comerciales en el orden internacional, las cuales se mantuvieron dentro de la misma dinámica (Herbold, 1973 y Tamtaleán, 1983). La Hacienda Pública o Finanzas Públicas, se insertaba en un marco exportador y dependiente; en el orden interno el Perú iniciaba su etapa republicana con la explotación de recursos naturales primarios (especialmente, minerales) como principal actividad económica, al no haber desarrollado España en sus colonias una economía industrial. La estructura estatal aún se encontraba

4 Para el desarrollo de este acápite usaremos los trabajos de Arce (1990) y Salas (2016) que se han detenido de caracterizar, etapas y contextos específicos en la historia del presupuesto público republicano y moderno. 
atrapada por la «herencia colonial», lo cual significó un lento desarrollo de los instrumentos de administración y gestión de lo público 5 . Por la fuerte presencia militar en el gobierno central, que generaba aparte de gastos operativos, demasiada discrecionalidad en priorizar los gastos de manutención de la milicia sobre el resto de las áreas estatales.

Tras la independencia, la Hacienda Pública a través del Presupuesto Gubernamental busca un equilibrio financiero entre el gasto y el ingreso; pero la realidad política y estatal del país dificultaba llegar a este principio presupuestario básico. Hipólito Unanue Primer Ministro de Hacienda, de la historia peruana, expresaba su preocupación por la situación de la hacienda pública en su memoria de 1822, no solo para mantener el ejército libertador de San Martín al que se añadían los auxiliares de Bolívar; el problema se agrava. Así, en dicho años se pidió el primer empréstito a Inglaterra por 1'200,000 libras esterlinas, comenzando la triste situación de resolver los problemas internos de la Hacienda Pública con los empréstitos. Pues ni la Cámara de Comercio, ni el Banco de Rehabilitación y Rescate en favor de la minería tuvieron éxito. La Casa de la Moneda no acuñaba ni la mitad del numerario que en tiempos de la dominación española y el circulante comenzó a disminuir.

En coincidencia con el proceso de modernización iniciado, el Estado peruano impuso algunos cambios que sus efectos fueron materia de debate entre economistas y políticos. El primero de ellos fue la implementación del régimen presupuestario cuyo cumplimiento fue sin embargo discontinuo y defectuoso. En los primeros ańos de la vida independiente, según Basadre, no existió un presupuesto, el primer esbozo de presupuesto se realizó recién en el gobierno de La Mar con José de Morales Ugalde a la cabeza del Ministerio de Hacienda. El primer presupuesto que contó con la aprobación del Congreso fue el del bienio 1848-49, promulgado en marzo del 1848.

El periodo que denominamos etapa hacendaria tradicional, se caracteriza por mantener aún una estructura enraizada en el modelo administrativo virreinal y los conceptos de Hacienda que regían en aquella época. En lo que respecta al Presupuesto Gubernamental se inscribían en la lógica de la Hacienda Pública en su sentido clásico, vinculado a las ideas administrativas de un estado mínimo que tiene por únicas funciones: a) Defensa de sus fronteras, b) Justicia y Seguridad Interior (Policía) y c) Algunas acciones que considera que el sector privado no puede asumir (ayuda social en educación, salud y alimentación).

La Hacienda Pública en este periodo se entiende según Duverger (1960) como «la ciencia de los medios por el que el Estado se procura y utiliza los recursos necesarios para la cobertura de los gastos públicos, mediante el reparto entre los individuos de las cargas resultantes» (pp. 9 y 10). Sin embargo, al no existir aún una adecuada organiza-

$5 \quad \mathrm{Al}$ respecto hemos propuesto el término «gestión de lo público» para poder rastrear en términos historiográficos la evolución de las herramientas de administración y gestión pública en el Perú republicano. Ver al respecto nuestro artículo sobre el particular (Saravia, 2018), citado en la bibliografía. 
ción estatal que pudiera establecer los gastos, sumada a la arbitrariedad del gobernante de turno en la época caudillista, que caracterizaba la fijación del gasto público se recurría a la fijación de impuestos que por lo general recaían en las masas ciudadanas y cuando eran insuficientes a las clases superiores de la sociedad ${ }^{6}$.

Como señala Salas (2016) durante los primeros veinticinco años de la República (1821-1846) no se planificó el ingreso público, ni mucho menos se controló su gasto porque «el desarrollo del Estado y el gasto público corrían a cargo de la voluntad y los deseos del caudillo de turno, y en ese sentido, los gastos militares consumían el grueso de los ingresos» (pág. 29).

En este escenario es interesante notar como el Ministerio de Guerra, posteriormente Ministerio de Guerra y Marina, mantuvo una presencia significativa y absorbía una importante cantidad del gasto para el mantenimiento de los pertrechos militares y el salario de los oficiales. Gradualmente en atención a necesidades específicas del Estado es que se tiene que reorientar el gasto público y crear instituciones de carácter más técnico y que cubran determinadas demandas sociales.

El periodo 1825-1840, está marcado por la búsqueda del diseño constitucional y aún la ausencia de presupuesto. La regulación del proceso hacendario y presupuestario de aquellos años se orienta por las normas generales de las cuatro primeras constituciones políticas: las de 1823, 1828, 1834 y 1839, en tres grandes aspectos: 1) el poder administrador, recae en el ejecutivo, tanto en las atribuciones, del Presidente de la República y el Ministro de Hacienda; 2) se fijan los aspectos de la administración y la organización estatal, en sí el procedimiento y las instancias por las que pasa la aprobación del presupuesto gubernamental; y 3) las atribuciones del poder fiscalizador, recaen en el Congreso, como ente de control político.

La Constitución de 1823 fijó como ente responsable de la elaboración del presupuesto al Ministerio de Hacienda, «quien debía presentar anualmente al Congreso: los planes orgánicos de Hacienda en general y de sus oficinas en particular; el presupuesto de los gastos precisos para el servicio de la República, y, el plan de contribuciones ordinarias para cubrir ese gasto, $y$, el de las extraordinarias para satisfacer los empréstitos nacionales y sus réditos correspondientes (Salas 2016, p. 28). La Constitución de 1826 por su parte, de carácter presidencialista, «colocó al Ministerio de Hacienda bajo la autoridad del presidente, mientras que en paralelo no creyó en la necesidad de un presupuesto, sino que cada secretaría formule su propio presupuesto (Salas 2016, p. 29). Con un diseño tan poco claro para llevar las cuentas del Estado «la pobreza generalizada obligó a los gobiernos caudillistas a reimplantar el tributo y la esclavitud para salvar las arcas fiscales y los campos de cultivo de la costa» (Salas 2016, p. 20).

6 Es esta actitud de fijar impuestos de manera arbitraria lo que generó el «antagonismo entre el Fisco y los particulares» que señalaba Juan Espinoza en su Diccionario para el pueblo (1855), y que ha perdurado hasta nuestros días 
En lo que respecta a la Administración y la Organización Pública, en la capital de la República se contará con una Contaduría General. En ella deberán examinarse, glosarse y fenecerse las cuentas de todos los productos e inversiones de la Hacienda (artículo $152^{\circ}$ ). Igualmente, en la capital de la República se estableció una Tesorería General, compuesta por un contador, un tesorero y los empleados correspondientes. Se reunirán en ella todos los productos de la hacienda (artículo 153 ). Se estableció en la capital de la República un Banco General de Rescate de oro y plata, y Bancos de Rescate en los principales asientos de minas para facilitarle la pronta explotación y beneficio de los metales (artículo 159 ).

El Congreso, conforme al artículo $60^{\circ}$ de la Constitución, tiene entre sus atribuciones: establecer modelos de pagar la deuda pública; decretas las contribuciones, impuestos y derechos para el sostén de la República; arreglar anualmente las tarifas de los gastos públicos en vista de los datos suministrados por el poder ejecutivo; abrir empréstitos en caso necesario dentro o fuera de la República pudiendo empeñar el crédito nacional, examinar y aprobar la inversión de los caudales públicos. Esta estructura se mantendría en la Constitución de 1828, aunque precisándose aspectos en materia presupuestal y de hacienda como veremos más adelante.

La Cámara de Diputados tiene exclusiva iniciativa de las contribuciones, negociar los empréstitos y para extinguir la deuda pública; quedan para el Senado la facultad de admitirlos, rehusarlos u objetarlos (artículos 240); y merece preferencia del Congreso garantizar la deuda pública: su consolidación y amortización (artículo $170^{\circ}$ ).

El Poder Ejecutivo, por su parte, tenía las siguientes atribuciones: el Presidente de la República debe estar en el país, durante su encargo y seis meses después de su ejercicio, y no puede salir del país sin permiso congresal (artículo $91^{\circ}$ y $92^{\circ}$ ). El Ministerio de Hacienda debe enviar anualmente a la Cámara de Diputados el estado genera de los ingresos y egresos del Tesoro Nacional y asimismo, el presupuesto general de todos los gastos públicos del año entrante con el monto de contribuciones y rentas nacionales (artículo 99 $9^{\circ}$.

Si bien en las Constituciones se señala que el ejecutivo presente el Plan Hacendario o Presupuestal al Congreso, hasta 1845 no se dio cumplimiento a esta disposición a excepción de 1830 en que el ministro José María del Pando remitió el Presupuesto de Gastos para el año siguiente, el mismo que no fue debatido.

A grandes rasgos los aspectos más resaltantes de las Constituciones de 1823, 1828, 1834 y 1839 en el orden hacendario, pueden resumirse de la siguiente: 1) se dispone la presentación del documento (plan hacendario) o presupuestal por el Ejecutivo para que el Congreso lo analice y apruebe; 2) el control de lo toma de cuentas corre a cargo del Congreso, debiendo igualmente señalar las contribuciones y autorizar los empréstitos; 3) la duración del ejercicio presupuestal y su control de cuentas es anual, aunque la aprobación del Presupuesto es bienal; 4) el Poder Administrador (Ejecutivo) cuenta con 
una Contaduría General, una Tesorería General, se suprimen las aduanas internas que dan el nacimiento a una Aduana General por lo menos para el despacho de los principales productos y su anotación tributaria respectiva; 5) la imposición se dice que es proporcional, sin privilegio alguno; 6) hay una preocupación reiterativa sobre la deuda púbica sea para negociar, consolidar y/o extinguirla; y 7) las Juntas Departamentales están presentes en la Constitución de 1823 y 1828, en lo concerniente al reparto de contribuciones, y a la toma de conocimiento de los ingresos y egresos del departamento para hacer las observaciones al Ministerio de Hacienda. Es pertinente adicionar la situación de las Prefecturas, que si bien no eran miembros natos de estas Juntas Departamentales, abrían anualmente las acciones y las instruían por escrito de los negocios públicos, considerando que en estos organismos políticos funcionan las oficinas de cajas o tesorería del Estado (Arce 1990, p. 69).

El periodo 1840-1860, tiene como característica el gran crecimiento económico generado por el guano y el endeudamiento del país. Por ello, se hizo necesario establecer un sistema administrativo más coherente y eficiente, es así que surge el primer intento formal de crear un presupuesto público. Para Arce (1990) entre 1846 y 1962, se inicia una nueva modalidad en el orden hacendario, puesto que ahora los presupuestos son presentados por el Ejecutivo como proyectos al Congreso, los cuales deberán ser aprobados para su ejecución. Además, la Hacienda Pública se relaciona con la economía en su conjunto, a través de «la producción del guano» $\mathrm{y}$ «el inicio de las obras públicas» (pág. 75).

Sin embargo, en la implementación de este nuevo modelo se presentaron muchos problemas de carácter técnico e inexactitudes. El Proyecto de Presupuesto de 1846, adolecía de un mal diseño pues «en el resumen publicado en el diario El Peruano que situó el ingreso anual en 5961639 pesos y los egresos en 4191 800, aunque en el propio oficio de remisión al Ministro se señalaba que los ingresos no llegaban a sumar los cuatro millones de pesos, y «que por otra lado no se incluyó en los egresos parte de los sueldos devengados por los empleados públicos y pensiones de civiles y militares, como tampoco los gastos generados por la Tesorería de Lima, la deuda con Colombia y Chile, los saldos de la guerra civil y otros gastos sin cubrir».

El ramo de hacienda experimentó un engrosamiento del gasto, ello debido a la mala gestión administrativa desde el mismo Ejecutivo. Como nos recuerda la autora «el gobierno de Echenique justificaba las operaciones de la deuda pública con el argumento de que se reducían los intereses del $6 \%$ al $4 \%$ de acuerdo a la ley de la Consolidación». Es ahí donde se hacen oír algunas voces alertas a la ahora visible corrupción enquistada en el poder, Domingo Elías, uno de los hombres más ricos de aquel entonces, «envió cartas públicas» al presidente Echenique, denunciando este escándalo financiero» que concluiría con el golpe de Estado propinado por Castilla a Echenique (Salas 2016, p. 39). 
Haciendo un análisis de los presupuestos de 1846 a 1861 desde la perspectiva del gasto público, es más que evidente que el fuerte crecimiento del gasto público fue producto del «boom guanero». Lo que permitió entre otras cosas cancelar la deuda externa en lo referente a Chile, deuda del ejército del San Martín, así como con Venezuela y Ecuador que pertenecieron a la Gran Colombia para la ayuda del ejército de Simón Bolívar. Se iniciaron las obras públicas, el ferrocarril Lima-Callao y Tacna-Arica, asimismo se instruyó a prefectos y gobernadores litorales, a través de una circular de 12 de octubre de 1848, sobre la preferencia que debía darse a obras circunscritas a la agricultura y el comercio. Se dio inicio en el país el afán de las obras públicas muchas veces sin sentido (Arce, 1990, p. 88).

Para el periodo 1862-1869, no encontramos la promulgación de ningún presupuesto hasta 1861. En el periodo anterior, el Presupuesto Gubernamental y su financiación se cubrió, en su mayor parte, con la exportación y venta del guano de las islas. El carácter provisional del gobierno de Castilla de 1858 a 1861, impidió que se promulgase un presupuesto antes. En el presupuesto de 1861-1862 los ingresos se incrementaron hasta alcanzar los 20763035 pesos y en contraposición los egresos fueron de 16456 018 pesos.

El «boom guanero» originó un clima de mayor atención a los temas fiscales entre la aún incipiente sociedad civil, así como propició la «unión entre capital comercial y el financiero» que dio lugar a los primeros bancos con capital nativo, y emisión periódica de material contable y estadístico oficial. Aparecieron en este periodo los textos de Manuel Atanasio Fuentes La estadística general de Lima (1858) y Cuestiones civiles. I. Apuntes sobre los registros del estado civil y la necesidad de organizarlos en el Perú (1868), en 1862 apareció el «Mercurio» como diario comercial y político, por decreto de 1855 el gobierno ordenó levantar «una carta geográfica de la República y la topografía de sus límites con el Ecuador y con Bolivia y otros puntos que se señalarían», el Atlas Geográfico de del Perú de Mariano Felipe Paz Soldán apareció en Paris en 1865 y el Mapa Mural del Perú de 1862 fue premiado por la Exposición Internacional de Paris, por su parte Mateo Paz Soldán, hermano menor de Mariano, con apoyo del Estado, publica Geografía del Perú en 1862. En lo que respecta a las entidades bancarias, aparece el banco «La Providencia» (1862) con un capital de 500000 pesos, el «Banco del Perú» (1863) con un capital de 10000000 de pesos, y el «Banco de Lima (1869) con un capital de 3200000 soles. Para la década de 1860, aparecieron los primeros bancos privados extranjeros especializados en el crédito al comercio ultramarino y en la remesa de fondos entre Hispanoamérica y Europa, de los cuales destacaba el banco británico «Banco de Londres, México y Sudamérica» cuya hegemonía en Hispanoamérica se mantuvo en forma exclusivo hasta 1880. El principal objetivo de estos bancos se concentraba en facilitar préstamos al Estado. 
En palabras de Miriam Salas, el diseño del presupuesto revela que, desde 1845 a 1878, la explotación del guano sostuvo la economía del país (pág. 44) por ello existió mayor regularidad en la promulgación de los presupuestos nacionales y las cuentas estatales, sobre todo por la especialización de las funciones del Ministerio de Hacienda. En junio de 1863, durante el corto periodo de gobierno Pedro Diez Canseco, se promulgó el presupuesto 1863-1864. En 1867, los ingresos, según las cuentas levantadas en el Ministerio de Hacienda, continuaron creciendo hasta alcanzar los 22246410 de soles y en paralelo con la misma rapidez los hicieron los egresos al llegar al 26534241.

El periodo 1869-1972, se encuentra por un lado afrontando las consecuencias del terremoto del 13 de agosto de 1868 y una crisis económica anunciada por el Ministerio de Hacienda tras el endeudamiento y la mala gestión de los recursos provenientes del guano. Los empréstitos se incrementaron en el periodo 1870-1872 para afrontar la crisis. La aprobación del presupuesto del periodo 1871-1872, no llegó a aprobarse debido a las fuertes irregularidades que generaba al Congreso las cláusulas del contrato Dreyfus. Por tal motivo el Ministerio de Hacienda se vio forzado a mandar abrir a los diversos ministerios de Estado un crédito mensual por la cantidad de 2457618 soles 40 centavos que al año sumaban 29491 420, 80, que al bienio ascendían a 58982 841, 60 soles. Los ministerios por aquel entonces estaban conformados por: el Ministerio de Relaciones Exteriores, el Ministerio de Gobierno, Policía y obras Públicas, el Ministerio Justicia, Instrucción y Beneficencia, el Ministerio de Guerra y Marina, y el Ministerio de Hacienda y Comercio. Los bancos incrementaron su presencia en la escena política nacional.

Entre 1860 y 1875, 17 casas bancarias abrieron sus puertas. La casa Dreyfus abrió un banco con el Estado como accionista. Justificando esta decisión de la siguiente manera: "por el ensanche de la actividad industrial el establecimiento de un nuevo banco y las ventajas que puede obtener el Estado tomando participación, en él mucho más si se atiende al provecho que hoy producen los bancos de emisión y descuento ya establecidos, ha resuelto de acuerdo con el nombre de Banco Nacional del Perú» (p. 79). La información contenida en el presupuesto de 1873-1874 no es del todo exacta para dar cuenta de todos los préstamos asumidos por el Estado para cubrir el déficit fiscal al término de este periodo. Durante el gobierno de Balta, no cesaron las exigencias del Estado por préstamos a los bancos.

El punto decisivo de este periodo es la promulgación de la Ley de Presupuesto de 1879, porque es con esta Ley que adopta de forma definitiva la idea moderna de Presupuesto Gubernamental. En esta norma se detallan las instituciones que intervienen en la creación y aprobación del presupuesto 1879-1880. El Ministerio de Hacienda, el Congreso, y el Ejecutivo, quedan consagrados como los entes responsables de diseñar el Presupuesto General de la República. La asignación presupuestal a los diferentes ministerios queda dividida en dos partes: Presupuesto Ordinario y Presupuesto 
Extraordinario, empezando un periodo de perfeccionamiento de las herramientas administrativas que será interrumpido por la Guerra con Chile.

Para autores como Arce (1990), el periodo 1873 a 1919 está marcado por dos momentos: 1) el «intento de afianzamiento liberal y crisis económica» (1873-1894) y 2) «La recuperación económica y el orden administrativo» (1895-1919). La ocupación del Gobierno chileno y la crisis económica en la que quedó el país tras la guerra retrasaron notoriamente el sistema administrativo y hacendario.

Los presupuestos gubernamentales de 1895 a 1912 resultan modestos en comparación con los montos de los años 1873-1874 que oscilaban entre 40000000 y 60 000000 de soles. Fueron con todo dieciocho años de incremento (400\%) pero que no alcanzaban los montos alcanzados en el siglo XIX. Se consiguió ir saliendo de la crisis gracias a la convergencia de intereses entre los intereses extranjeros y el gobierno civilista que puso una política monetaria y tributaria a favor de proveer recursos al capital para fomentar las inversiones.

Representativo de esto es el mensaje del entonces presidente Manuel Pardo en las Cámaras Legislativas el 28 de julio de 1876, en donde expresa sus opiniones sobre el Estado y el Fisco:

(...) mi gobierno ha encontrado en el orden político basado en la fuerza material que lo sostenía; el orden económico y social en los dispendios del Tesoro; el orden fiscal en los descuentos del porvenir (...) He ahí el resumen de nuestro pasado y el punto de partido del presente periodo, que ha debido buscar para el orden político otra base para la fuerza; para el orden fiscal otra base de un crédito agotado; para el orden económico y social, la base del trabajo propio, en vez de los dispendios del Tesoro Público ${ }^{7}$.

Sin embargo, como han señalado Arce (1990) y Salas (2016), el mismo grupo civilista se nutrió de esta forma de ver las finanzas públicas y de diseñar el presupuesto gubernamental durante la época del guano. Debido a la corrupción enquistada en los altos cargos de la administración pública (Quiroz, 2013 y Salas, 2016), los mecanismos de control y el diseño en sí eran mal en la creación del presupuesto eran mal vistos por el reducido grupo de ciudadanos en entender los tecnicismos. Un testimonio de los problemas presupuestales de la época, desde una perspectiva técnica, nos la brinda Lino Cornejo (1907) cuando señala que:

(...) el principal de los males que ocasiona este procedimiento la aprobación congresal es que nuestro presupuesto carece de orientación y de unidad. No es organismo, es un agregado de partidas, una colección de gastos [b]otados sin plan, sin ideas precon-

$7 \quad$ Citado en Arce (1990, p.203, nota 235). 
cebidas (...) no obstante de que anualmente se notan considerables aumentos, porque faltan un plan de obras y una escala de saldos que concilien el estado del Tesoro y las necesidades nacionales. El remedio, de urgencia incuestionable en materia de presupuesto.

El presupuesto es una herramienta de gestión de carácter técnico, por ende, sus criterios técnicos y las formalidades legales de su ejecución por sí solas no podían dar resultado sin previamente estos obedecer a una finalidad estatal, es decir, empleando un término moderno, que formen parte de una política pública de inversión y de distribución del gasto. Que en aquellos años era inexistente. En cierta medida el gobierno de Guillermo Billinghurst intentó dar algo de orientación al gasto presupuestal en especial el gasto social, sin embargo, su caída impidió que estas reformas pudieran materializarse. El contexto de la primera Guerra Mundial a su vez disminuyó la capacidad de innovación en materia presupuestaria.

\subsection{Etapa Moderna (1920-1974)}

Siguiendo a Arce (1990) este periodo se divide en dos etapas bien marcadas: 1) Sub Etapa Modernista; y 2) Sub etapa desarrollista. El Estado inicia un crecimiento inusitado del gasto público, que para los países como el Perú se materializa en una alta inversión en obras públicas sin fijarse en una orientación adecuada y establecer criterios de inversión. Es recién en el Gobierno de Benavides y con el apoyo de la Comisión Kemmerer, que las inversiones adquieren una clara orientación. Aunque, es recién para la década de los cincuenta en donde las inversiones y los préstamos externos tienen una dirección definida.

El presupuesto gubernamental asume características de no ser solo un elemento contable-administrativo, pues se convierte en un instrumento regulador de la vida financiera del Estado y de la economía en su conjunto (Arce, 1990, p.216).

\subsubsection{Sub Etapa Modernista (1920-1959)}

Esta etapa corresponde a un Estado que, si bien se encuentra en la perspectiva moderna, aun es insuficiente para adecuarse al creciente sector público nacional. Dentro de los hechos más notorios sobre el presupuesto gubernamental tenemos que se pone en marcha el Fondo Nacional de Desarrollo Económico con todas las variantes de Juntas y Corporaciones.

Se crean organismos importantes como el Instituto Nacional de Planificación y la Oficina de Racionalización Administrativa. Se nacionaliza la Caja de Depósitos y Consignaciones S.A.Y se produce la dación del Presupuesto por Programas, segunda Ley Orgánica del Presupuesto General N 4598 (1922) que continuó rigiendo con 
posteridad a 1959. Esta Ley General fue sustentada por Abraham Rodríguez Dulanto en la Cámara de Diputados, demostró en opinión de Arce (1990) que fue un conjunto de disposiciones avanzadas que tuvieron validez en las Finanzas Públicas por cuarenta ańos, "convirtiéndose en un instrumento de previsión financiera» que tenía por objetivo «racionalizar al sector público en crecimiento» (p. 220). La ley Orgánica de Presupuesto representó la base para las leyes anuales, que debieron ser sancionadas por el Congreso y discutidas pliego por pliego con el ministro responsable. Por su parte, el Ministerio de Hacienda centraliza la etapa de formulación, con reuniones de comisiones del Congreso, constará el documento presupuestal de la cuenta, previsión y valuación de todas las entradas y gastos de la nación que se presentará en tres títulos: 1) De los Ingresos divididos en capítulos sobre: la renta de impuestos directos, la renta de impuestos indirectos, monopolios y explotaciones; rentas y productos de dominio del Estado y recursos extraordinarios; 2) De los Gastos, dividiéndose en pliegos (Ministerios y Cámaras), a su vez el pliego se subdividirá en capítulos o series, y estos a su vez, en partidas o servicios aislados; y 3) El Balance, el cual no debía presentar déficit.

Arce (1990) señala que desde el punto de vista estrictamente técnico presupuestal la ley consagró los siguientes principios:

a) Unidad: por la que se establecía un presupuesto único, es decir sin separaciones de ordinario y extraordinario.

b) Universalidad: en que todos los ingresos y egresos del Estado deben figurar en el documento presupuestal.

c) Integridad: el que establece el monto bruto, tanto del ańo fiscal como el de su liquidación.

d) Especificidad: en cuanto a que los gastos deben ser aplicados a finalidades concretas y de carácter ministerial.

e) Periodicidad y equilibrio: es anual y busca la no existencia de déficits (Arce, 1990, p.222).

Como complemento a la Ley Orgánica del Presupuesto se creó en 1929 la Controlaría General de la República y en su Ley Nº 6484 del 28 de febrero de 1930, se le encargó la realización de auditorías; sus funciones se dirigían al control de los aspectos financieros, en particular de los fondos públicos.

La Constitución de 1920 establecía que el Congreso impone las contribuciones, reconoce la deuda pública y seńala los medios para consolidarla y amortizarla autoriza al Ejecutivo para que negocie empréstitos empeñando la Hacienda Pública y designando fondos para su amortización. Luis Castillo (1972) se refiere sobre este contendido de la Carta Magna, de la siguiente manera: «contiene la ominosa autorización de empañar la Hacienda Pública Nacional y de comprometer las rentas generales del Estado» (p. 63). 
Establecía además que el Ejecutivo a través de sus ministros presentara al Congreso ordinario al momento de su instalación, una memoria sobre el ramo a su cargo, e informar al Congreso sobre la marcha del Portafolio. Correspondiéndole al Ministro de Hacienda presentar la Cuenta General de la República al Congreso correspondiente del año anterior y a su vez del siguiente, con la aprobación del Consejo de Ministros. Ambos documentos debían remitirse en el mes de agosto de cada año y su omisión haría responsable al Gabinete en su conjunto. Todos estos aspectos fueron reglamentados por la Ley $\mathrm{N}^{\circ} 5591$ del 23 de diciembre de 1924. Con estas modificaciones de la Ley en mención, se hacía imperativa la concurrencia de los Ministros de Estado a la Discusión y Aprobación de sus respectivos pliegos presupuestales.

Las organizaciones creadas principalmente en el Oncenio de Leguía (1919-1930) dieron un carácter moderno al marco institucional público, es así como producida la crisis de 1930 llegó al Perú la Misión Norteamericana Kemmerer, la cual examinó la Hacienda Pública y sus opiniones no fueron de crítica sino más bien de aceptación de muchos planteamientos viabilizados por el Leguiísmo, como fue el caso concreto del Presupuesto Gubernamental y de la Contraloría General.

En la Constitución de 1933 persiste la orientación y el carácter financiero del presupuesto gubernamental; pues, sigue siendo un instrumento estrictamente financiero, que llega a efectivizar a los más un control contable, y a la obligatoriedad del Ejecutivo de presentar la Cuenta General de la República como balance de gastos e ingresos, y otras operaciones financieras del Estado.

Con la Ley $\mathrm{N}^{\circ} 8929$ del 25 de julio de 1939 en su artículo $12^{\circ}$ se precisa que el Ministro de Hacienda dentro de los 30 días siguientes a la instalación de la Legislatura Ordinaria remitirá a la Cámara de Diputados el Proyecto de Presupuesto para el año próximo, enviará también al Senado y la Cámara de Diputados, la Cuenta General correspondiente al ańo fiscal anterior con el informe del funcionario encargado del control de la operación del Presupuesto.

Por la Ley N 8488 del 30 de Diciembre de 1936, se crea el Servicio de Presupuesto que se convirtió en la Dirección de Presupuesto, del Ministerio de Hacienda y Comercio; los considerando de este servicio fueron datos para modificar la confección del Presupuesto General de la república a fin de que éste responda a las normas técnicas, con estadío permanente de los ingresos y egresos y que cooperase con la formulación anual del indicado Presupuesto, las cuales fueron: 1) clasificar científicamente los diferentes pliegos del Presupuesto General de la República; 2) estudiar permanentemente la marcha de ingresos y egresos, consignando mensualmente sus resultados; 3) recoger de la Superintendencia de Bancos, Consulados, Cámaras de Comercio, las posibilidades de ingresos; 4) estudiar las partidas no específicas del Presupuesto General de la República, para conocer si están o no bien calculadas; 5) estudiar los Pliegos de las Compañías Fiscalizadas en cuanto a sus ingresos y egresos; 6) informarse de los Bancos y otras ins- 
tituciones, en que el Estado sea coparticipe de la marcha de los ingresos y dar cuenta al Ministerio de Hacienda de las observaciones anotadas; 7) recopilar las leyes tributarias, decretos, resoluciones, contratos, créditos activos y pasivos y demás leyes que afecten al Presupuesto General de la República; 8) centralizar la información de los documentos arriba mencionados, antes del $1^{\circ}$ de Junio de cada ańo para la Formulación del Proyecto de Presupuesto, y entregar al Ministro de Hacienda la Proforma del Presupuesto de Ingresos y Egresos que se asigne a cada Ministerio, sugiriendo las disposiciones financieras que juzgue necesarias para obtener el equilibrio presupuestal; 9) revisar e informar sobre los Presupuestos Administrativos a los diversos ramos, antes de la Aprobación por el Gobierno; 10) ver los aspectos de transferencias, aperturas de créditos suplementarios y extraordinarios que se acuerden en los diferentes Ministerios, así como la respectiva comunicación a la Contraloría General de la República; 11) formar la estadística de ingresos y egresos públicos; 12) el Director de Presupuesto presentará un informe mensual escrito, con los datos numéricos sobre la manera como se viene ejecutando el Presupuesto; y 13) la creación de la Dirección de Presupuesto en este período reafirma el deseo que el Sector Púbico se modernice y asuma funciones de carácter más específico, y por tanto, vaya conformando una organización que responsa a una mayor racionalidad.

\subsubsection{Sub Etapa Desarrollista (1960-1989)}

En esta subetapa se inicia el "desarrollo» entendido como crecimiento económico, y particularmente que, a través del Sector Público, pues se da un mayor ritmo a las inversiones, principalmente en la tarea de las grandes construcciones que para los líderes del desarrollismo era preocupación crear la infraestructura física necesaria para iniciar el ansiado despegue. Son los años donde se comparte el esfuerzo desarrollista y el despertar de las expectativas, a todo ello se acompañan altos índices de crecimiento de la población nacional.

Se pone en marcha el Fondo de Desarrollo Económico, a través de las Juntas y Corporaciones creadas por la Ley N 12676, del 11 de Diciembre de 1956, la cual tenía como objetivos construir y mejorar las vías de comunicación, los canales de regado en favor de la mediana y pequeńa agricultura, dotación de agua y desagüe, pavimentación y establecimiento de servicios complementarios (mercados, saneamiento, etc.) de preferencia en capitales de circunscripción, asimismo en la construcción y establecimiento de pozos sanitarios, y en la formación de rutas de expansión urbana. En síntesis, las Juntas y Corporaciones llevaron las siguientes líneas de trabajo: a) el tipo de construcciones en beneficio de las capitales de circunscripción que concuerda con su «inscripción caciquista ha dado a los representantes de la mayoría grandes facilidades, en la práctica para disponer a su criterio de los recursos»; b) la misma Ley en su artículo $15^{\circ}$ entrega el Plan de Obras a la Junta Departamental de Obras Públicas, que obedecía a los intereses de la capital de Departamento, olvidándose de los distritos y caseríos; c) 
las Juntas Departamentales en el transcurso de 1959 a 1968 se fueron constituyendo en "Corporaciones de Desarrollo», sea por las catástrofes, terremotos y/o por la decisión de los grupos políticos ubicados en el Poder Legislativo; d) es pertinente aclarar que el Fondo de Desarrollo Económico se creó como Ley complementaria a la Ley Orgánica del Presupuesto General de la República N 4598 dada el 27 de diciembre de 1922 pero su comportamiento presupuestal atendiendo la magnitud de la inversión no tuvo una presentación detallada de la ejecución de metas físicas en las Cuentas Generales de la República; y e) su desaparición es en 1972 por Decreto Ley N 18896 al crearse el Sistema Nacional de Apoyo a la Movilización Social que absorbe no solo el FNDE sino a las Corporaciones Departamentales y Juntas de Obras Públicas.

Se crea el Instituto Nacional de Planificación (INP) con la finalidad de establecer los lineamientos de la economía en su conjunto, considerando los acuerdos en 1960 de Punta del Este. El INP comienza sus actividades en 1962.

La complejidad del Sector Público obligó a la dación del DL No 14260 del 21 de diciembre de 1962 (Ley Orgánica del Presupuesto Funcional) que resultó una ley de bases de avanzada en cuanto al presupuesto, financiero y programáticos; esta Ley dividió al Sector Público Nacional en: Gobierno Central; Sector Público Descentralizado; y Gobiernos Locales. Estableciéndose las fases del proceso presupuestario: a) Programación; b) Formulación; c) Aprobación; d) Ejecución; y e) Control Financiero y de Resultados.

El artículo $15^{\circ}$ de la mencionada norma especificó que el INP debía decidir sobre el Presupuesto de Metas y sus relaciones con el Presupuesto Financiero. Con posteridad se expidió la Ley Orgánica $N^{\circ} 14816$ que no tuvo el alcance del Decreto Ley $\mathrm{N}^{\circ} 14620$. En cuanto a la planificación y programación, tanto la ley $\mathrm{N}^{\circ} 14816$ y sus leyes conexas $\mathrm{N}^{\circ}$ : 15257, 15682 y 16360 en su conjunto expresaron: a) Un carácter reglamentarista en la ejecución y control contable, reflejaba la mayor importancia que se daba a los aspectos financiero que a los programáticos, y b) El INP y las Oficinas Sectoriales sólo participaban en el proceso de programación al nivel de Informe previo en la Formulación del Anteproyecto del Presupuesto Funcional (artículo $20^{\circ}$ de la Ley $\mathrm{N}^{\circ} 14816$, quedando el recto de la etapa de Formulación (artículo $24^{\circ}$ de la Ley $\mathrm{N}^{\circ}$ 14816) bajo consulta y gestión de las Direcciones Administrativas, del Ministerio de Hacienda y el Congreso.

Estas disposiciones legales expresaron la tendencia indicada, pero en la práctica el Parlamento desde 1963 intervino más allá de los límites de lo que significaba un proceso programático del Sector Público trayendo abajo cualquier intento planificador.

Entre 1963 y 1968 se expidieron disposiciones y se crearon instituciones que expresaran el deseo de racionalizar el comportamiento del sector público dentro del marco que la situación imponía, como fue la puesta en marcha de la Oficina de Racionalización Administrativa (en adelante, ONRA), la nacionalización de la Caja de Depósitos y 
Consignaciones S.A. para restablecer el Banco de la Nación, aunque las entidades del sector público en cuanto a sus transacciones continuaron hasta 1969 girando cuentas a los bancos del Sector Privado; finalmente, con posterioridad a la crisis del 1967 se dieron otras disposiciones como el nuevo Código Tributario (1966) y lo referente a la captación ingresos para el Estado, principalmente a través del Decreto Supremo N²87$68 \mathrm{HC}$.

Por Decreto Supremo N³7-F en agosto de 1963 se creó la Comisión Interministerial de Cooperación Popular, luego Dirección de Cooperación Popular y Desarrollo Comunal y finalmente Dirección General de Promoción Comunal, esta se dio en el marco desarrollista, aprovechando a su vez de la generosa participación entrega de los campesinos en las construcciones de sus obras, se le adicionó al llamado desarrollo comunal con el fin de buscar la integración al país de los pueblos olvidados y marginados.

Según Arce (1990) el esfuerzo de los servidores públicos de la COOPOP para que se cumpliera la política indicada, a nivel de poder ejecutivo (1963-1968), contra los intereses del poder legislativo y grupos económicos, se logró que la micro planificación sea entendida como un proceso de participación de la población en el análisis y conocimiento de la realidad basada en el deseo de lograr que ese proceso de "movilización» de mano de obra se amplíe para llegar a construir un verdadero proceso educativo. Ello implica que no debe haber más obras físicas sin su explícita contrapartida de actividad educativa, lo más directamente posible, con uno u otro factor de la infraestructura socio-económica del desarrollo.

La Organización de las Naciones Unidas define el Sistema de Presupuesto por Programas en los siguientes términos: «Una clasificación de Presupuesto por Programas, es un sistema en que se presta particular atención a las cosas que un Gobierno realiza, más que a las cosas que adquiere. Las cosas que un Gobierno adquiere, tales como: servicios personales, equipos, servicios de transporte, etc., no son, naturalmente, sino medos que emplea para el cumplimiento de sus funciones. Las cosas que un Gobierno realiza, en cumplimiento de sus funciones pueden ser carreteras, escuelas, hospitales construidos, soldados preparados, tierras bonificadas, casos tramitados y resueltos, permisos expedidos, exposiciones celebradas, informes preparados o cualquiera de las innumerables cosas que se pueden definir. Lo que no queda aclarado en los sistemas presupuestarios tradicionales es esta relación entre las cosas que el Gobierno adquiere y las cosas que realiza.

Dada la naturaleza de los gobiernos de este periodo vinculados con del desarrollismo el Presupuesto por Programas, adquirió rápidamente una gran difusión y aplicación, ya que consistía en un documento que muestra las finalidades del Gobierno en forma de programas concretos de acción, en los que señalan los objetivos y las metas que se esperan lograr y los medios y recursos necesarios para alcanzarlos. 
En la lógica de la época el Presupuesto por Programas era un instrumento que cumplía su propósito de combinar los recursos disponibles en el futuro inmediato tras la meta de con plazo, concedido para la ejecución de los objetivos de largo y mediano plazo, establecidos en los planos y programas de desarrollo. El Presupuesto por Programas, conjugaba el concepto tradicional de responsabilidad en el manejo de fondos públicos, por el concepto de responsabilidad en el cumplimiento de las metas y las que esos fondos se han asignado. Las metas o resultados físicos se convierten paralelamente en los aspectos financieros del gasto, en objeto de la actividad presupuestaria (Arce 1990, p. 264).

Los años ochenta fueron el último de la subetapa desarrollista, y fue una década particularmente difícil debido a la crisis económica internacional, en donde quedó claramente demostrado la dependencia existente de las cuentas fiscales y el entorno internacional. Por lo que los gobiernos de Fernando Belaunde Terry (1980-1985) y Alan García Pérez (1985-1990) afrontaron una crisis económica en medio de la efervescencia social producto de la vuelta a la democracia, y un contexto propicio para la inversión en políticas y programas sociales largamente demandados por la población. Con la constitución de 1979, el camino estaba más que roturado para que se aplicaran políticas sociales.

Los primeros síntomas de la crisis se dieron en 1983, en donde la responsabilidad del Ministerio de Economía recayó en Carlos Rodríguez-Pastor Mendoza, un tecnócrata vinculado al gran capital internacional (había sido presidente del Wells Fargo International Bank), quien abrumado por la crisis cedió a un plan de restructuración propuesto por el Fondo Monetario Internacional (en adelante, FMI) para lograr un crédito de 500 millones de dólares. El reajuste incluía reducción del gasto público, mayor restricción de la demanda e incremento del ritmo de devaluación y de los tipos de interés. Pero estos esfuerzos no sirvieron de mucho por las necesidades que tuvo Belaunde de inflar el aparato estatal con más trabajadores y sus proyectos en obras de infraestructura, como la Marginal de la Selva, postergada por la dictadura militar. Esta situación se vio agravada por la naturaleza, ya que se produjo la irrupción del fenómeno de El Niño (1982-1983).

Si bien se mantenían los formalismos legales y constitucionales para la aprobación y puesta en ejecución del presupuesto, las circunstancias políticas y económicas, flexibilizaron cuando no pasaron totalmente por alto las normas legales. Esto es más que notorio en el gobierno de García que abrumado por la hiperinflación y el peso de su decisión de dejar de pagar la deuda externa, incluyó medidas económicas paliativas a la crisis que llevaron a contabilidades totalmente irreales para el gasto público y que hacían imposible la proyección y la planificación para salir de la crisis. 


\subsection{La Etapa Contemporánea: Las Reformas y los tecnicismos 1993- hasta la actualidad}

Tras el desastroso gobierno de García, y con la victoria de Alberto Fujimori, se da un proceso de reforma que significó la reestructuración del Estado, y la aparición de un nuevo modelo estatal que tomará el modelo privado como modelo de eficiencia y buscará incluirlo en el sistema estatal. Es la Constitución de 1993 la que da el nuevo régimen económico, y que posiciona al Ministerio de Economía y Finanzas (MEF) como el principal actor político en la elaboración del Presupuesto Público. A la par, al consolidarse los criterios técnicos sobre los políticos en la elaboración del presupuesto y la orientación del gasto público. Es así que actores políticos internacionales como el FMI y el Banco Mundial quedan plenamente consolidados como actores políticos intervinientes en la elaboración del presupuesto.

En el Perú la política de gasto ha estado supeditada al equilibrio de las cuentas públicas en un marco de objetivos antiinflacionarios y de requerimientos de las negociaciones de la deuda externa, y no ha generado mayores modificaciones en la formulación y control del presupuesto.

\section{Los principales actores en la elaboración del presupuesto}

Se debe tener en cuenta que los intereses de los individuos agrupados en un mismo poder o sector muchas veces entran en conflicto entre sí, y ello genera importantes implicancias en la distribución de recursos y en la aplicación de las políticas públicas. Así, a medida que los sistemas políticos evolucionan y los sistemas electorales se hacen más complejos, se hace necesario analizar con mayor detalle los objetivos y restricciones de cada actor político interviniente en la planificación y creación del gasto publico. Para poder visualizar el tipo de comportamiento estratégico que seguirán, el cual tendrá efecto sobre el monto total a gastar, su distribución y la eficiencia del gasto.

Tradicionalmente desde el lado de la economía para el caso peruano se han considerado la existencia de 10 tipos de «jugadores» (3 grupos dentro del propio Ejecutivo) los cuales se encuentran en cuatro esferas: el poder Ejecutivo, el Congreso, el Poder Judicial y la sociedad civil (Carranza, Chavez y Valderrama, 2007).

Así los actores que desde el ejecutivo tiene injerencia en la elaboración del presupuesto son: 1) Presidente de la República; 2) el Ministro del MEF y 3) las distintas unidades ejecutoras del gasto. El resto de los actores políticos son: 4) el Congreso, 5) el poder Judicial, 6) los Partidos Políticos, 7) los grupos de Interés, 8) los movimientos sociales (incluido los sindicatos), 9) la sociedad civil y 10) Los actores políticos internacionales. 
A nivel de poder legislativo, la aprobación del presupuesto es un mecanismo de control al Ejecutivo. Al integrarse de una pluralidad de actores ha sido en algunos casos difíciles la aprobación del presupuesto antes de los noventa. Sin embargo, la prohibición de la constitución de 1993 de la capacidad del Congreso de incluir nuevos gastos en el presupuesto. Es a través de la Comisión de Presupuesto en el esquema actual donde se plasma con mayor claridad las tensiones subyacentes en los parlamentarios, como representantes que son de una pluralidad de intereses políticos y económicos.

El poder Judicial interviene como actor dinámico a través de sus decisiones judiciales. Para entender su papel como actor político, es necesario ponerlo en relación con su vinculación con partidos políticos y grupos de interés diversos, en el contexto actual se ve con mayor nitidez como la captación de las instituciones es una realidad, ya sea por intereses políticos o por simple corrupción.

Los grupos de interés, a diferencia de los partidos políticos, intentan afectar las decisiones de políticas públicas, pero sin participar directamente en el gobierno. Estos grupos defienden intereses gremiales, sectoriales, regionales, etc., y lo hacen a través de métodos directos como el lobby (conversación directa con líderes políticos) o tratando de influir a través de métodos indirectos, tales como marchas, huelgas, o usando a los medios de prensa para conseguir el apoyo de la opinión pública y forzar a una solución a sus reclamos. En la práctica, los grupos de interés tienen aliados políticos (congresistas o incluso ministros) que interactúan con ellos y presionan dentro del Ejecutivo o el Congreso al MEF para obtener mayores recursos o mayores exoneraciones. Cuando se percibe que existen mayores ingresos fiscales, hay una tendencia a proliferar estos pedidos.

La fuerza relativa de los diferentes gremios ha ido cambiando a lo largo del tiempo, quizás en forma más drástica, pero con igual tendencia que en el resto de la región. Así, la reforma de la legislación laboral a principios de los noventa (que básicamente consistió en flexibilizar los despidos y redujo los costos relativos no salariales del empleador para trabajos temporales), y la necesidad de competir en un mundo más globalizado, llevó a la recomposición de la estructura laboral, implicando una reducción drástica de la fuerza laboral sindicalizada, con lo cual las "centrales de trabajadores» y los sindicatos en general perdieron bastante poder, y solo en ańos recientes se aprecia un leve resurgimiento del movimiento sindical. Por sí solo, el movimiento sindical no ejerce mucha presión, pero en su alianza con otros movimientos sociales si consiguen convertirse en actores políticos con poder.

Finalmente, las potencias mundiales y los organismos supranacionales ejercen históricamente presión en las políticas de los países, en temas presupuestarios no son la excepción. Su injerencia se da de diversas maneras ya sea a través de la capacitación técnica de funcionarios del gobierno, convenios bilaterales y multilaterales, empréstitos o a través de la coerción a través de sanciones o bloqueos comerciales. 


\section{Conclusiones}

John Lewis Gaddis (2004) en una lúcida e inteligente metáfora sobre la historia y el quehacer del historiador nos dice que: «si el tiempo y el espacio proporcionan el campo en que la historia sucede, la estructura y el proceso proporcionan el mecanismo» (pág. 59). Pues es a partir de las estructuras que sobreviven en el presente como los historiadores reconstruimos procesos que nos son inaccesibles por el paso del tiempo.

Al hacer esta primera aproximación sobre la evolución del presupuesto público en nuestro país, hemos partido de la estructura estatal para rastrear como los actores políticos han intervenido históricamente en la perfección de esta herramienta de gestión. En el camino, nos hemos topado con una historia alejada de secuencias normativas sobre el particular, sino interacción de actores políticos en pugna en el seno del Estado.

El presupuesto público, es una herramienta de gestión que es parte de los procesos de control del Congreso al Ejecutivo, e históricamente se ha ido perfeccionando para restringir su poder y discrecionalidad.

La evolución del presupuesto público va de la mano con el momento de desarrollo que experimente el Estado y al peso relativo de ciertos actores políticos en un momento determinado. Así, a mayor poder del ejecutivo más discrecionalidad en el gasto y menos desarrollo de elementos técnicos y administrativos de gestión. En contraposición mayor cantidad de actores intervinientes mayores mecanismos formales para la creación y ejecución presupuestal.

El perfeccionamiento de herramientas de gestión como el presupuesto público pueden entenderse como una lógica de supervivencia estatal, en la línea de análisis de Anthony de Jasay (1993), para quien el Estado es un organismo viviente independiente de los actores políticos que lo componen y con intereses que pueden ser incluso hasta contrarios con estos. Por ello, la pluralidad de actores intervinientes en la creación y ejecución del gasto público es un proceso que tiene que ver con la cesión de poder del Ejecutivo y la necesidad de los actores de flexibilizar sus exigencias al estado, para que este superviva. Tradicionalmente, la ciencia política entiende que el Estado adopta los intereses de la clase o grupo social que toma el poder. Sin embargo, es la práctica actores políticos y Estado se necesitan mutuamente para plasmar sus intereses.

El peso político de cada actor es variable, por ello en países como el nuestro de poco desarrollo industrial, y subordinado en buena parte al contexto internacional, actores como el FMI y el Banco Mundial influyen mucho más en las políticas presupuestarias que la sociedad civil, ministerios o el Congreso.

Se hace necesario el desarrollo de una línea de investigación de historia administrativa o gubernamental, que pueda poner en perspectiva la implementación de las herramientas técnicas de gestión con la historia política y la evolución de los derechos sociales, ya que componen un bloque de análisis que se ha atomizado por el análisis cor- 
toplacista del impacto de las políticas y la gestión públicas en espacios locales. Estudios que son importantes también, pero que, al omitir perspectivas de largo plazo, obvian la presencia de elementos de la cultura política nacional que supervivieron a sucesivas reformas del estado, como fue en su momento la corrupción.

\section{Referencias}

Aljovín, C. (2000). Caudillos y constituciones. Perú: 1821-1845. Lima: IRA-PUCP / FCE.

Basadre, J. (1969). Historia de la República. XVI Tomos. Lima: Editorial Universitaria.

Castillo, L. (1972). Finanzas públicas. Lima: Cia de Impresiones y publicidad S.A.

Cobián, E. (2015). «La constitucionalización del derecho presupuestario y la protección de los derechos fundamentales: apuntes para la reflexión en el Perú». En Pensamiento Constitucional $\mathrm{N}^{\circ} 20,2015$, pp. 161-184.

Carranza, L.; Chávez, J. y Valderrama J. (2007). La economía politica del proceso presupuestario: El caso peruano. Lima: Instituto Peruano de Economía.

Contreras, C. (2012). La economía pública en el Perú después del guano y del salitre. Crisis fiscal y elites económicas durante su primer siglo independiente. Lima: BCR / IEP.

Cornejo, L. (1907). El presupuesto en el Perú. Lima: Librería Escobar e Imprenta E. Moreno.

Duverger, M. (1960). Instituciones financieras. Barcelona: Editorial Bosh Casa Editorial Urgel.

Fukuyama, F. (2004). La construcción del Estado. Hacia un nuevo orden mundial en el siglo XXI.

Gaddis, J. (2002). El paisaje de la Historia. Como los historiadores representan el pasado. Barcelona: Anagrama.

Jasay, A. de (1993). El Estado. La lógica del poder política. Madrid: Alianza Editorial.

Kresalja, B. y C. Ochoa (2017). Derecho constitucional económico. Lima: PUCP.

Manchego-Muñoz, J. (1981). Indice analítico de la Constitución Política de 1979. Lima: Editorial Andina.

Mostajo, R. (2002). El Sistema Presupuestario en Perú. Serie Gestión Pública, 17. CEPAL.

Napurí, C. (2003). Las relaciones de Gobierno entre el poder Ejecutivo y el Parlamento. Lima: PUCP.

Eguiguren, F. (2007). La responsabilidad del presidente. Razones para una reforma constitucional. Lima: PUCP.

Espinoza, J. (2001[1855]). Diccionario del pueblo. Lima: PUCP / University of the South-Sewanee.

Saravia, J (2018). «La gestión pública en el Perú en perspectiva histórica (siglos XIX-XXI)». En En Lineas Generales, Año I, N², pp. 143-161.

Parsosn, P. (2007). Politicas públicas. Una introducción a la teoría y la práctica del análisis de politicas públicas. México: FLACSO.

Quiroz, A. (2013). Historia de la corrupción en el Perú. Lima: IEP / IDL. 
Stiglitz, J. (2003). La semilla de la destrucción. La década más próspera de la historia como causa de la crisis económica actual. Buenos Aires: Taurus.

Tantaleán, J. (1983). Politica económica-financiera y la formación del Estado: siglo XIX. Lima: Ediciones CEDEP. 